\title{
PENSAR LA TRADUCCIÓN Y EL FEMINISMO NEGRO - ENTREVISTA CON OCHY CURIEL
}

\author{
Dennys Silva-Reis [D.S-R.] ¿Tiene usted alguna experiencia com la práctica de \\ traducción feminista?
}

Ochy Curiel [O.C.] Si. Con Jules Falquet tradujimos los aportes de las feministas materialistas francesas Colette Guillaumin, Paola Tabet y Nicole Claude Mathieu, condensada en el texto El Patriarcado al desnudo, tres feministas materialistas, que salió publicado en el año 2005 a través de la editorial independiente Brecha lésbica.

Posteriormente el Grupo Latinoamericano de Formación y Acción Feminista (GLEFAS), colectivo del cual formo parte, tradujo el texto La invención de las mujeres. Una perspectiva africana sobre los discursos occidentales del género" de la nigeriana Oyèrónkẹ́ Oyěwùmí en el año 2017, a través de nuestra editorial, también independiente, en la frontera.

\section{[D.S-R.] ¿Cree que la profesión de traductora e intérprete es sexualizada? ¿Cuales serían las causas y las consecuencias de ello?}

[O.C.] Cómo sucede en toda la sociedad occidental, las relaciones sociales son generalmente sexistas, racistas y clasistas. Tiene que ver con las jerarquías que se han construido desde los inicios de la colonización que continua en la colonialidad contemporánea y la traducción no escapa de esto. Es parte del sistema modero/ colonial. Los conocimientos más validados son los que producen los hombres blancos con privilegios de clase, aunque también algunas mujeres con estos privilegios también. Eso significa que esos conocimientos son los que también se validan para que sean reconocidos en muchas partes del mundo a través de la traducción que se hace de sus obras.

Ochy Curiel

La profesora Ochy Curiel,

Nació en República Dominicana, luego de vivir en México, Brasil y Argentina, actualmente vive en Colombia. Doctora en Antropología Social. Es docente-investigadora de la Universidad Nacional y de la Universidad Javeriana en Bogotá, Colombia y es también consultora independiente.

Es activista del movimiento lésbico-feminista, antirracista, del feminismo autónomo y del feminismo decolonial y también cantautora. Es miembra del Grupo Latinoamericano de Estudios, Formación y Acción Feminista (GLEFAS), de la Tremenda Revoltosa, batucada feminista y del Colectivo Globale Bogotá, festival de documentales críticos. Tiene varias publicaciones en la que imbrica la raza, el sexo, la clase, la sexualidad y le geopolítica en la que se destaca su libro: La nación heterosexual, Análisis del discurso jurídico y el régimen heterosexual desde la antropología de la dominación (2013).

Dennys Silva-Reis

Doctor en Literatura (Universidad de Brasília - UnB). E-mail: reisdennys@gmail.com 
[D.S-R.] ¿En su opinión, hasta qué punto la noción de género de una dada cultura se puede traducir a otra cultura?

[O.C.] Tal como los explicó la argentina Maria Lugones a través de su concepto colonialidad del género, el género es una categoría moderna colonial pues se reconoce el diformismo sexual entre hombres y mujeres, desde las experiencias de mujeres y hombres blancos/as y burgueses/as, por tanto, no es universal. En muchas otras culturas no existe el género, ni siquiera las categorías de hombres y mujeres. Un ejemplo de ello es lo que explica Oyèrónkẹ Oyěwùmí en su texto La invención de las mujeres en torno la sociedad Yorùbá del suroeste de Nigeria. El género no existia en estas sociedades antes del contacto con occidente, fue impuesto a través de la colonización europea.

\section{[D.S-R.] ¿Le parece que haya una distinción entre traducción femenina y traducción feminista?}

[O.C.] Por supuesto. Lo femenino es una cualidad resultado de la diferenciación que trae consigo la heterosexualidad que se asume la tienen las mujeres, lo cual es un error, pues los hombres también pueden tener cualidades que se asumen como femeninas. Al final son construcciones sociales. Una traducción feminista implica una postura política, aunque esto también es problemático porque no existe solo un tipo de traducción feminista. Todo depende en cual corriente del feminismo se inscribe la traducción.

\section{[D.S-R.] ¿Cuál sería la importancia de la traducción de teorías feministas en el mundo contemporáneo?}

[O.C.] Creo que muchos feminismos han aportado a complejizar los análisis de las relaciones sociales. Hay feminismos, como el feminismo negro, el feminismo decolonial que permite contextualizar la situación de grupos a quienes no solo les afecta el género, sino también la raza, la clase, la sexualidad, la geopolítica de forma imbricada de acuerdo a contextos específicos. La traducción de estas teorías son importantes precisamente para no generalizar ni universalizar las experiencias, que ha sido el error del feminismo hegemónico que ha sido blanco en sus teorías y conceptos y que solo toma como centro del análisis el género desde las experiencias de las mujeres blancas, generalmente del Norte.

\section{[D.S-R.] ¿Cuál es su opinión acerca de traducción y activismo (intelectual o no)?}

[O.C.] Creo que es fundamental para poder fortalecer las coaliciones transnacionales. Los y las activistas debemos hacer traducción de obras y propuestas que nos ayuden a comprender mejor la complejidad de las relaciones sociales. Creo importante traducir no solo las obras con una visión crítica desde al Norte hacia Sur, sino del 
Sur hacia el Norte. Por ejemplo, hemos conocido las producciones de las feministas afronorteamericanas porque han sido más traducidas que las que hemos producido las afrolatinas y afrocaribeñas, y eso se debe a que Estados Unidos sigue siendo un centro privilegiado del saber, lo cual responde a la geopolítica del conocimiento, aunque sea desde grupos subalternos. En el Norte deben conocer nuestras propuestas, como una forma de descolonizar el saber.

[D.S-R.] ¿La circulación de ideas feministas por medio de traducción impulsiona la emancipación de otros grupos de mujeres?

[O.C.] Por supuesto. Y no solo de mujeres, sino de otros grupos subalternizados. En la medida que conocemos las experiencias de otros grupos en muchas latitudes, eso ayuda a tener una mejor comprensión de las experiencias diversas, y también de las luchas y resistencias que se hacen en muchos lugares y eso aporta para la coalición transnacional, como dije antes.

[D.S-R.] ¿Está de acuerdo com que solo mujeres blancas pueden traducir a mujeres blancas y solo mujeres negras pueden traducir a mujeres negras?

[O.C.] No. Considero que, aunque las mujeres negras debemos hacer mayor traducciones de otras mujeres negras, no se trata de esencializar este ejercicio. Existen pensamientos, teorías, conceptos tanto de mujeres negras y mujeres blancas que son críticos e interesantes para nuestros proyectos políticos y que son importantes traducir. Lo que creo es que las mujeres blancas tienen mayores accesos y privilegios y muchas veces toman las experiencias de las mujeres negras como meros testimonios o materias primas para sus créditos académicos, por eso es importante que las mujeres afrodescendientes e indígenas hagamos traducción de la producción de nuestras compañeras para evitar la utilización y la instrumentalización de nuestras experiencias y pensamientos.

[D.S-R. ¿ Cree que hombres (feministas o no) son sensibles y aptos para traducir textos femeninos y feministas? Cuales serían los retos y las potencialidades involucradas en este caso?

[O.C.] Mi respuesta a esta pregunta es similar a la pregunta anterior. Depende de cuáles hombres. Hay hombres que tienen privilegios de raza, clase, sexualidad, geopolítica, pero hay otros que no, como la mayoría de hombres afros e indígenas de nuestro continente y en ese sentido pueden ser nuestros aliados, sobre todo si tienen posiciones políticas parecidas a las nuestras. Lo importante es saber cuál es la intensión de la traducción que tienen. 
[D.S-R.] ¿Acaso existen, en su opinión, agendas feministas compatibles con estructuras de publicación editorial? Como se podría buscar una equidad de género en este campo?

[O.C.] Creo que existen políticas editoriales feministas diversas. No hay una sola línea editorial y no creo que todas se limiten a buscar la equidad de género. Hay propuestas feministas que son antirracistas, descoloniales, como existen otras, diría que la mayoría, que no lo son.

[D.S-R.] ¿En la historia de la traducción se conocen a pocas traductoras e intérpretes mujeres, sobre todo negras. ¿Conoce usted algunos nombres? ¿Nos podría hablar de ellas?

[O.C.] Creo que hay muy pocas, sobre todo negras y afros. Quienes hemos hecho traducciones, lo hacemos desde el activismo, no como parte de un ejercicio profesional.

[D.S-R.] ¿Acaso habría, en su opinión, una "culpa de la traducción" por haber más teoría feminista blanca difundida en el mundo?

[O.C.] Considero que no se trata de "culpa de traducción", sino de las posibilidades y el acceso. La mayoría de las mujeres negras, afros, indígenas de nuestro continente no tienen suficiente dinero, ni tiempo, para priorizar la traducción de textos. Tampoco existen muchas editoriales interesadas en traducir sus obras. Creo más bien que es una cuestión estructural que tiene que ver con al colonialidad del saber, aunque por suerte, cada vez más algunas entendemos la importancia de traducir textos de la gente negra e indígena para dar a conocer sus pensamientos y luchas.

[D.S-R.] ¿Puede la traducción contribuir a la renovación de la literatura canónica feminista en las distintas áreas de las humanidades?

[O.C.] Por supuesto, sobre todo si son traducciones de las obras de la gente subalternizada. Es lo que va a contribuir a descolonizar el saber feminista y de las ciencias humanas a nivel general.

[D.S-R.] ¿Acaso conoce proyectos de traducción feminista no-hegemónicos? En caso positivo, nos podría decir cuales son y como funcionan?

[O.C.] Pues uno de ellos es lo que estamos haciendo en el GLEFAS, desde nuestra editorial en la frontera, y lo que ha hecho Brecha Lésbica. Ambas son editoriales independientes.

[D.S-R.] ¿Que consejos daría para un lenguaje (traductorio) menos sexista? 
[O.C.] Pues buscar maneras de escritura que no reflejen la ideología de la diferencia sexual, el binarismo degénero, pero igual hay que hacerlo desde una postura decolonial, eso significa evitar categorías, conceptos, palabras racistas, coloniales, heterosexuales y sobre todo que sea una traducción apegada a los significados que quien produce y no una sustitución de palabras y conceptos occidentales. El lenguaje también es político.

[D.S-R.] ¿Cuál sería una buena metáfora para la traducción feminista (negra)?

[O.C.] La amefricanidad de Leila González.

[D.S-R.] ¿Es posible enseñar a traducir el feminismo o a hacer una traducción feminista?

[O.C.] Sí, pero todo depende de qué tipo de feminismo. No todos son iguales y una traducción puede ser feminista, pero puede ser bastante racista. Creo que es posible desarrollar metodologías que permitan una traducción decolonial. 